\title{
Comparative Research on Application of Interactive Whiteboards (IWBs)in K-12 Schools Between Britain and China
}

\author{
Kang Cui ${ }^{\mathrm{a}}$, Ju Huimin ${ }^{\mathrm{b}}$, Wang Lina ${ }^{\mathrm{c}}$ \\ ${ }^{a}$ School of Educational Technology, Beijing Normal University, Beijing, China \\ ${ }^{b}$ Electronic and Information Technology Training Center, Beijing Union University, Doctor in Beijing Normal \\ University \\ ${ }^{c}$ School of Education Technology, Beijing Normal University
}

\begin{abstract}
Since Interactive whiteboards (IWBs) was firstly applied to k-12 schools in Britain, the related research has increasingly developed in China, and significant findings has achieved in both countries. For a further discussion, the comparative research method on this issue is employed, together with introduction and analysis of application of IWBs in Britain and China. It comes to the following conclusions: (1) application IWBs in China is still in the first stage against Britain. (2) Systematic research supported by the integrity of government, universities and teachers makes IWBs much applicable in Britain, but China still has a long way to go in this field. (3) China concentrates on its functions as a tool excessively, rather than pays more attention to the way of how to use it. (4)Some potential utility in instructional design associated with teachers-students interaction should be considered or discussed even more. Anyway, IWBs with its inherent characteristic, tends to play an important role in teaching.
\end{abstract}

Index Terms: interactive whiteboards (IWBs); application; k-12 schools; Britain and China

(C) 2012 Published by MECS Publisher. Selection and/or peer review under responsibility of the International Conference on E-Business System and Education Technology

\section{Introduction}

With the development of technology, e-media are increasingly concerned, and make educational technology researchers meet some challenges about how to choose and use them in enabling teachers to facilitate teaching activities. With public increasing concerned interactive learning, IWBs has acted as an important media to teachers' instruction.

\footnotetext{
* Corresponding author.

E-mail address: ${ }^{\text {ccountry001@126.com }}$
} 


\section{The main functions of interactive whiteboards}

IWBs was initially developed for and used in the business sector, but not applied to schools until the late 1990s [1]. It's obviously true that IWBs has improved the physical environment and psychological environment of schools, and increased active interactions and discussion between teachers and students, students and students.

IWBs includes almost advantages that has been showed in

blackboard and multi-media computer teaching system, and we could also benefit from it in the following items:(1) Writing, teachers and the students could write in their own ways, without worrying pollution from chalks. (2) Demonstrating and annotating, teachers could demonstrate pictures, sounds, videos and animations, as well as annotate these materials at any time during teaching activities. (3) Saving contents, teachers could save drawn graphics, written words, inserted pictures among the whole classroom teaching. (4) Spotlighting, drawing curtain, and amplification/reduction, teachers could make students interest in learning through covering, focusing on or zooming out the contents of courses diversely.

\section{The application of interactive whiteboards in british schools}

British people are keening on improving new instructional media. James Piraeus, the headmaster of old Edinburgh middle school and English educationist, invented the first real blackboard and applied it to geography courses. Currently, Great Britain is still in the forefront of applying interactive whiteboards into class, and use IWBs most widely in the world. The author has documentarily focused on related research written, reported or engined by British Educational Communications and Technology Agency (Becta)[2], ProQuest database[3], as well as ISI web of Knowledge database with the key words "interactive whiteboard".

\subsection{Infrastructure construction}

Becta, a governmental organization, has creatively promoted the technology throughout learning in an effective way. According to the results studied by Becta in October, 2003, the percentage of IWBs in primary schools, middle schools, and special schools was $48 \%, 82 \%$ and 53\%, respectively, and the results also indicate that, IWBs is one of the most frequently used CAI media in K-12 schools, followed after LCD projectors and digital cameras [4].

IWBs has won higher appraisal from the British government, and lots of research reports prefer approving classroom environment with help of IWBs, by which small class teaching could be conducted easily and effectively. Because of small class size and unfixed seat in, IWBs equipment could be diversely arranged, for example, in the front, middle or sides of the classroom, etc. All of these makes teachers and students use IWBs possibly and acceptably. By 2007, $98 \%$ of middle schools and all of the primary schools are provided with IWBs $[5]$.

\subsection{Instructional advantages}

Recent studies indicate that IWBs have two main advantages for teaching. Effectively and efficiently improving teaching activities, such as operation, visibility, easy-to-use, flexibility and versatility, help teachers to pay more attention to instructional design and to use instructional strategies freely in one hand; Facilitating students' study as the other, especially in stimulating students' learning mentally and physically, giving full play to students' subjective initiative, adaptive to students' digital culture as well [6][7].

British government pays more attention to influence of the appearance of new media and technology which potentially affect teachers' sense of teaching efficacy compared to traditional or conventional ways. Therefore, lots of studies on ICT supporting teachers' instruction have been done and achieved a lot in reducing the 
disadvantageous influences. Meanwhile, for a easy use of IWBs and to cater for different grades and different subjects using IWBs, separate functions and manipulation rules have been set; examples for illustrating interactive process between different groups of teachers and IWBs, students and students, students and resources, students and teachers have been shown, too[8][9][10] [11].

\subsection{Hierarchy of application}

Five levels of basic, developmental, familiar, proficient and creative have been divided in distinguish teacher's skill of using IWBs during teaching activities [12]. Basic (Level 1): take IWBs as just a tool or substitute of blackboard; Developmental (Level 2): teachers could operate computer with some special functions to develop interactive teaching activities; Familiar (Level 3): All additional functions could be available and IWBs are frequently used as a useful way. Proficient (Level 4): teachers continue to broaden their repertoire of tools and techniques and experiment with the unique pedagogic potential of the interactive whiteboard using high levels of creativity. Creative (Level 5): teachers are true virtuoso performers with a wide repertoire of tools, techniques and student interactions. Their lessons are characterized by the variety of techniques deployed, the fluency with which they move between them and high levels of interaction with students.

\subsection{Validating the effect}

How much the new technology will improve students' study after it being brought into classroom instruction? Does it make the teaching effective, efficiency and appealing comparing to the conventional media? These questions are considered constantly by educational technology researchers.

After applying IWBs in elementary education, British government estimates the effects every year by authorizing related organizations or researchers in different ways, e.g. investigations, interviews, case studies, and so on. The results are published in the form of reports, for example, the final report on Embedding ICT in The Literacy and Numeracy Strategies by Centre for Learning and Teaching School of Education, written by Communication and Language Sciences University of Newcastle upon Tyne in 2005, the research report on Evaluation of the Primary Schools Whiteboard Expansion Project in 2007, etc.

There are also other experts which always study the essence of IWBs. The researchers from Newcastle University studied behavior change of teacher-students interaction through 184 literacy and numeracy lessons (including lessons with IWBs and lessons without IWBs). It turned out that teaching with IWBs had seemingly affected the whole class, but not obviously as the advocators said, and the technology itself could not bring substantial changes to traditional teaching styles [13].

Researchers studied the application of IWBs in science instruction, and they considered that IWBs could increase the pace and attraction of one lesson, trigger the attention of teachers and whiteboards, not the students' learning. It will be effective when the interactive technology extends to students-centered interactive pedagogics, which enable students be in the centre of study and teaching [14].Through analyzing literatures of IWBs, researchers think that good instruction is always good instruction, no matter whether it has technique to support or not. Technique may improve teaching only when teachers and students regard technique as a method to achieve the objectives and being willing to participate in the classes to understand its potential rather than technique itself [15].

\section{The application of interactive whiteboards in chinese schools}

The IWBs was introduced in schools increasingly after the experimental research project between UK and China, which was built in 2004 by professor Ding Xingfu, from Capital Normal University, China. In order to 
find out current research on IWBs in China, a engine of the China Academic Journal and Important conference Papers Full-Text Database (2000-2010) with the key words "whiteboard", "interactive " and "instruction", and a separate search of the China Doctors' and Excellent Masters' dissertations Full-Text Database(2000-2010) with the key words "interactive whiteboard" are conducted. Besides, the author has made a further investigation about the sales of IWBs in the schools.

\subsection{Infrastructure construction}

The financial investment of IWBs comes from the schools and local education bureau, which IWBs are introduced according to funds and need themselves. In China, IWBs are applied in large and medium-size cities of developed areas, including Beijing, Shanghai, Guangzhou, Shenzhen, Nanjing, and so on. Other remote areas are in initial stage, including Xinjiang province, Yunnan province, Heilongjiang province, and so on [16].

However, due to the influences of Chinese traditional organizational form of teaching and too many students in a class, IWBs has not played an important role in teaching. The author has investigated some schools which had equipped with IWBs, and come to some conclusions as: (1) IWBs are mainly located in front of the classroom, beside the platforms.(2) the environment of a classroom becomes more complex, with blackboards, IWBs and multimedia computer teaching system.(3)teachers use blackboards most frequently, multimedia computer teaching systems less, IWBs least.

\subsection{Instructional advantages}

Which advantages do IWBs has comparing with other conventional media, e.g. blackboards, projectors, multimedia computer teaching systems? Whether IWBs can take the place of them or not? Researchers have discussed a lot, and think that IWBs assemble the both advantages of blackboards and multimedia computer teaching systems, and can realize more humanistic instruction[17][18].The studies on IWBs focus on analyzing their functions, how to use IWBs in subject teaching, and application methods in subjects of Chinese, mathematics, English, science, etc. And these research results mainly come from summary of K-12 teachers' experience, e.g. Interactive Whiteboards and Map Instruction [19], Research on Optimizing Primary Mathematics lessons by Using IWBs [20], and so on.

\subsection{Hierarchy of application}

From macroscopic view, IWBs are regarded as not only a choice to achieve educational informatization, but also the best substitution way to realize School-to-School to classroom-to-Classroom [21]. From microcosmic view, there are three functions of IWBs itself, the substation of Blackboards, special functions of IWBs, and interactive functions of IWBs. Therefore, the Chinese researchers summarized three levels [22]. Level 1: substitution of blackboard, teachers only write and draw on it. Level 2: usage of special functions, teachers do some man-machine interaction. Level 3: developing the full interactive functions of IWBs.

\subsection{Validating the effect}

Researchers only have done some theoretic and experiential reflections on usage of IWBs, no empirical studies are involved.

\section{Conclutions}

(1) Application IWBs in China is still in the first stage against Britain. 
(2) Systematic research supported by the integrity of government, universities and teachers makes IWBs much applicable in Britain, but China still has a long way to go in this field.

(3) China concentrates on its functions as a tool excessively, rather than pay more attention to the way of how to use it.

(4)Some potential utility in instructional design associated with teachers-students interaction should be considered or discussed even more.

\section{References}

[1] Jan Lacina. Interactive Whiteboards: Creating Higher-level, Technological Thinkers? Childhood Education, Summer 2009 , pp.270-272,

[2] http:// research.becta.org.uk/

[3] http://proquest.umi.com/login?

[4] Li Zhitao, Li Zhenying. the New Development and Application of ICT in British Schools. Information Technology Education in K-12 schools, 2004 (3), pp.57-60.(in Chinese)

[5] Becta.Harnessing Technology, schools survey .2007, http://research. becta.org.uk /index.php? catcode=_re_rp_02\&rid=14110\&section=rh

[6] Steve Higgins, Chris Falzon, Ian Hall, etc. Embedding ICT In The Literacy and Numeracy Strategies (Final Report), 2005, http:// research.becta.org.uk/

[7] Schuck, S.\& Kearney.M..Exploring pedagogy with interactive whiteboards: a case study of six schools. At http://www.ed-dev.uts.edu.au/teachered/research/iwbproject/pdfs/iwbreportweb.pdf (accessed 5/06/08)

[8] Steve Higgins, Chris Falzon, Ian Hall, etc. Embedding ICT In The Literacy and Numeracy Strategies (Final Report), 2005

[9] David Barber, Linda Cooper, Graham Meeson. Learning and teaching with interactive whiteboards : primary and early years. 2007, At http:// research.becta.org.uk/

[10] Teaching Interactively with Electronic Whiteboards in the Primary Phase. At http:// research.becta.org.uk/ [11] Jenny Gage. How to use an interactive whiteboard really effectively in your secondary classroom. 2006, At http:// research.becta.org.uk/

[12] Centre for ICT, Pedagogy and Learning, Education \& Social Research Institute, Manchester Metropolitan University. Evaluation of the Primary Schools Whiteboard Expansion Project :Report to the Department for Children, Schools and Families.2007. At http:// research.becta.org.uk/

[13]Fay Smith, Frank Hardman, Steve Higgins. The impact of interactive whiteboards on teacher-pupil interaction in the National Literacy and Numeracy Strategies, British Educational Research Journal ,2006, Vol. 32, No. 3, pp. 443-457

[14] Hennessy S.,Deaney, R.., Ruthven, K. and Winterbottom, M..Pedagogical strategies for using the interactive whiteboard to foster learner participation in school science. Learning, Media and Technology, 2008, 32(3) , pp.283-301

[15] Higgins S.,beachamp,G.. and Miller,D..Reviewing the literature on interactive whiteboards. Learning, Media and Technology, 2007,32(3): pp.213-225

[16] www.tech.sina.com.cn/b/2010-04-27/14144117140.shtml.(in chinese)

[17]Ding Xingfu. Research on Interactive Whiteboards and its Application in Chinese K-12 classroom instruction. Chinese Educational Technology, 2005(3),pp43-46.(in Chinese)

[18] Wang Zhongzheng. Influences on Interactive Electronic Whiteboards Bring in Classroom Instruction. Chinese Medical Educational Technology, 2008(8),pp327-329. (in Chinese)

[19] Li Wanlong. Interactive Whiteboards and Map Instruction. Geography Education, 2007(6), pp64. (in Chinese) 
[20] Gan Lijun, Zhao Biru. Research on Optimizing Primary Mathematics lessons by using IWB. China Educational Modern Equipment,2010(6), pp62-65. (in Chinese)

[21]Ding Xingfu. Breach of Elementary Education Informatization: from School-to-School to Classroom-toClassroom. 2004(11), pp8-12. (in Chinese)

[22] Li Xinyu. Analyzing Hierarchy on Application Interactive Whiteboards in Classroom Instruction. Chinese Educational Techonology. 2005(3),pp52-54. (in Chinese) 